BNL-112715-2016-JA

\title{
Mechanism of Oxygen Reduction Reaction on Pt(111) in Alkaline Solution: Importance of Chemisorbed Water on Surface
}

\author{
Shizhong Liu, Michael G. White, and Ping Liu
}

Submitted to Journal of Physical Chemistry C

July 2016

Chemistry Department

Brookhaven National Laboratory

\author{
U.S. Department of Energy \\ USDOE Office of Science (SC), \\ Basic Energy Sciences (BES) (SC-22)
}

\footnotetext{
Notice: This manuscript has been authored by employees of Brookhaven Science Associates, LLC under Contract No. DE- SC0012704 with the U.S. Department of Energy. The publisher by accepting the manuscript for publication acknowledges that the United States Government retains a non-exclusive, paid-up, irrevocable, world-wide license to publish or reproduce the published form of this manuscript, or allow others to do so, for United States Government purposes.
} 


\section{DISCLAIMER}

This report was prepared as an account of work sponsored by an agency of the United States Government. Neither the United States Government nor any agency thereof, nor any of their employees, nor any of their contractors, subcontractors, or their employees, makes any warranty, express or implied, or assumes any legal liability or responsibility for the accuracy, completeness, or any third party's use or the results of such use of any information, apparatus, product, or process disclosed, or represents that its use would not infringe privately owned rights. Reference herein to any specific commercial product, process, or service by trade name, trademark, manufacturer, or otherwise, does not necessarily constitute or imply its endorsement, recommendation, or favoring by the United States Government or any agency thereof or its contractors or subcontractors. The views and opinions of authors expressed herein do not necessarily state or reflect those of the United States Government or any agency thereof. 


\title{
Mechanism of Oxygen Reduction Reaction on Pt(111) in Alkaline Solution: Importance of Chemisorbed Water on Surface
}

\author{
Shizhong Liu ${ }^{1}$, Michael G. White ${ }^{1,2}$ and Ping Liu²* \\ ${ }^{1}$ Chemistry Department, State University of New York (SUNY) at Stony Brook, Stony Brook, NY \\ 11794 (USA) \\ ${ }^{2}$ Chemistry Department, Brookhaven National Laboratory, Upton, NY 11973 (USA)
}

* To whom correspondence should be addressed.E-mail: pingliu3@bnl.gov; Tel: 631-344-5970. 


\begin{abstract}
We report a detailed mechanistic study of the oxygen reduction reaction (ORR) on $\mathrm{Pt}(111)$ in alkaline solution, combining density functional theory (DFT) and Kinetic Monte Carlo (KMC) simulations. A complex reaction network including four possible pathways via either $2 \mathrm{e}^{-}$or $4 \mathrm{e}^{-}$ transfer is established, being able to reproduce the experimental measured polarization curve at both low and high potential regions. Our results show that it is essential to account for solvation by water and the dynamic coverage of $* \mathrm{OH}$ to describe the reaction kinetics well. In addition, a chemisorbed water $\left({ }^{*} \mathrm{H}_{2} \mathrm{O}\right)$-mediated mechanism including $4 \mathrm{e}^{-}$transfers is identified, where the reduction steps via $* \mathrm{H}_{2} \mathrm{O}$ on the surface are potential-independent and only the final removal of *OH from the surface in the form of $\mathrm{OH}_{\text {aq }}^{-}$contributes to the current. For the ORR in alkaline solutions such a mechanism is more competitive than the associative and dissociative mechanisms typically used to describe the ORR in acid solution. Finally, $* \mathrm{OH}$ and $* * \mathrm{O}_{2}$ intermediates are found critically important for tuning the ORR activity of Pt in alkaline solution. To enhance the activity, the binding of Pt should be tuned in such a way that $* \mathrm{OH}$ binding is weak enough to release more surface sites under working conditions, while ${ }^{* *} \mathrm{O}_{2}$ binding is strong enough to enable the ORR via the $4 \mathrm{e}^{-}$transfer mechanism.
\end{abstract}




\section{Introduction}

Recent studies have shown progress in anion-exchange membranes that can alleviate $\mathrm{CO}_{2}$ poisoning, ${ }^{1-3}$ which makes the alkaline fuel cell (AFC) an option as a power source. Similar to the fuel cell in acid solution, platinum $(\mathrm{Pt})$ is the best metal catalyst for the oxygen reduction reaction (ORR) in the AFC. ${ }^{4}$ Extensive efforts in both experiment ${ }^{4-20}$ and theory ${ }^{6,21-38}$ have been made to study the underlying mechanism of the ORR on Pt in acid solution, while not as much attention has been paid to Pt-catalyzed ORR in alkaline solution.

The ORR on Pt in an alkaline environment generally operates in two different regions, the so-called inner- and outer-sphere. ${ }^{39}$ The outer-sphere process exhibits near-independence on a large number of electrode materials and therefore is non-electrocatalytic, where in most cases adsorbed hydroxyl species (*OH with * referring a surface site) promote the partial reduction of solvated $\mathrm{O}_{2}\left(\mathrm{O}_{2 \mathrm{aq}}\right)$ to the hydroperoxyl $\left(\mathrm{OOH}_{\mathrm{aq}}^{-}\right)$species via a $2 \mathrm{e}^{-}$transfer mechanism. ${ }^{40-41}$ The inner-sphere process is electrocatalytic in which chemisorbed $\mathrm{O}_{2}\left({ }^{* *} \mathrm{O}_{2}\right)$ at the Pt surface undergo a series of reductions to $\mathrm{H}_{2} \mathrm{O}$ and $\mathrm{OH}^{-}$aq via an efficient $4 \mathrm{e}^{-}$transfer mechanism. ${ }^{39-40}$ In order to achieve high ORR activity in alkaline media, it is important to tune the performance of the cathode catalysts to facilitate the $4 \mathrm{e}^{-}$transfer ORR at the inner-sphere, while limiting the $2 \mathrm{e}^{-}$ transfer reaction at the outer-sphere.

The electrocatalytic ORR in alkaline solution on Pt surfaces and/or particles have been proposed to operate via parallel mechanism as that in acid mainly based on rotating ring disk experiments. $^{42-43}$ There is no agreement regarding $\mathrm{pH}$ dependence. Differences in electrolyte and charge carrier $\left(\mathrm{H}^{+}\right.$vs. $\mathrm{H}_{2} \mathrm{O} / \mathrm{OH}^{-}$) are likely to lead to different behavior, e.g. surface sensitivity of Pt toward the ORR. ${ }^{42,44}$ Therefore the mechanism largely based on the ORR on Pt in acidic solution may not be adequate enough to describe. By identifying key reaction steps, such mechanistic study of the ORR can aid in the development of next generation catalysts, which are based on the non-precious metals and their oxides to greatly lower the cost and make the AFC more attractive. ${ }^{45-46}$

In the present study, we report a detailed mechanistic study of the electrocatalytic ORR at the inner-sphere in alkaline solution using theoretical calculations. The $\operatorname{Pt}(111)$ surface is chosen as a model system, since it has been found to be more active than $\operatorname{Pt}(100)$ and $\operatorname{Pt}(110)$ for the ORR in alkaline solution. ${ }^{47-48}$ In addition, the Pt nanoparticles are expected to be dominated by (111) facets. ${ }^{49-50}$ The combination of Density Functional Theory (DFT) and Kinetic Monte Carlo 
(KMC) simulations allows us to pinpoint the complex reaction network and reproduce the polarization curve measured by rotating ring disk experiments. ${ }^{51}$ One of significant findings is that the presence of water on the surface is essential to describe the reaction kinetics realistically. More importantly, the contributions from parallel $4 \mathrm{e}^{-}$transfer associative and dissociative mechanisms, typically considered for the ORR in acid solution, ${ }^{21}$ are unable to compete with a new mechanism discovered in this work involving ${ }^{*} \mathrm{H}_{2} \mathrm{O}$. In this newly identified pathway, $\mathrm{O}_{2}$ reduction via surface bound ${ }^{*} \mathrm{H}_{2} \mathrm{O}$ leads to the formation of $* \mathrm{OH}$, and the conversion of $* \mathrm{OH}$ to $\mathrm{OH}_{\mathrm{aq}}^{-}$is the only potential-dependent step involved. Finally, a sensitivity analysis shows that to improve the ORR activity of $\mathrm{Pt}$ in alkaline solution, the * $\mathrm{OH}$ binding with the Pt surface should be weakened to allow its facile removal and prevent ${ }^{*} \mathrm{OH}$-poisoning. At the same time, ${ }^{* *} \mathrm{O}_{2}$ binding should still be strong enough to promote the efficient $4 \mathrm{e}^{-}$transfer mechanism at the inner-sphere. Our study highlights the importance of modeling a realistic environment including surface water and accounting for multiple mechanisms in parallel.

\section{Methods}

\subsection{DFT Calculation}

DFT calculations were performed using Vienna Ab-initio Simulation Package (VASP) $)^{52-56}$ with projector augmented wave method, and the Perdew-Wang functional (GGA-PW91) within the generalized gradient approximation was used to describe exchange-correlation effects ${ }^{57-58}$. The cutoff energy was $500 \mathrm{eV}$ and convergence of energy and forces were set to $1 \times 10^{-5} \mathrm{eV}$ and $0.01 \mathrm{eV} / \dot{\mathrm{A}}$. Pt(111) was modeled by 4-layer slab with $3 \times 3$ atomic arrangement in each layer, where the bottom two layers of every Pt atoms were fixed and the top 2 layers of Pt and adsorbates were fully relaxed with the adsorbates. All the slab models included a vacuum of 20 $\dot{A}$. A $3 \times 3 \times 1$ Monkhorst-Pack was used for k-point sampling to describe the unit cell ${ }^{59}$. The transition states were searched by climbing image nudged elastic band method (NEB) method in VASP (VTST) $)^{60}$.

Inspired by the method developed by Nørskov and coworkers, ${ }^{21}$ we assumed the equilibrium of the reaction

$$
\mathrm{H}^{+}{ }_{\text {aq }}+\mathrm{OH}_{\text {aq }}^{-} \leftrightarrow \mathrm{H}_{2} \mathrm{O}_{\text {aq }}
$$


Assuming the coupling between an electron transfer to the electrode and the formation of $\mathrm{OH}_{\mathrm{aq}}^{-}$ $\left(\mathrm{OH}^{-}{ }_{\mathrm{aq}}-\mathrm{e}^{-}\right.$in our notation), Eq.1 was also expressed as $\left(\mathrm{H}_{\mathrm{aq}}^{+}+\mathrm{e}^{-}\right)+\left(\mathrm{OH}_{\mathrm{aq}}^{-}-\mathrm{e}^{-}\right) \leftrightarrow \mathrm{H}_{2} \mathrm{O}_{\mathrm{aq}}$. Using the standard hydrogen electrode (SHE) as the reference electrode, the free energy of $\mathrm{OH}^{-}$$\mathrm{e}^{-}, \mathrm{G}\left(\mathrm{OH}^{-}-\mathrm{e}^{-}\right)$, was then determined as

$$
\mathrm{G}\left(\mathrm{OH}_{\mathrm{aq}}^{-}-\mathrm{e}^{-}\right)=\mathrm{G}\left(\mathrm{H}_{2} \mathrm{O}_{\mathrm{aq}}\right)-\mathrm{G}\left(\mathrm{H}_{\mathrm{aq}}^{+}+\mathrm{e}^{-}\right)=\mathrm{G}\left(\mathrm{H}_{2} \mathrm{O}_{\mathrm{aq}}\right)-1 / 2 \mathrm{G}\left(\mathrm{H}_{2}\right)
$$

The corresponding free energy of reaction was calculated as

$$
\Delta \mathrm{G}=\Delta \mathrm{G}_{0}+\Delta \mathrm{G}_{\text {solvation }}+\Delta \mathrm{ZPE}+\text { neU }
$$

$\Delta \mathrm{G}_{0}$ was given by the standard definition as $\Delta \mathrm{G}_{0}=\Delta \mathrm{E}+\mathrm{T} \Delta \mathrm{S}_{0}$, where $\Delta \mathrm{E}$ was DFT-calculated reaction energy and $\mathrm{T} \Delta \mathrm{S}_{0}$ represented the entropic contributions. The contribution from solvation to the reactions involving aqueous species, $\mathrm{H}_{2} \mathrm{O}_{\mathrm{aq}}, \mathrm{OH}^{-}$aq and $\mathrm{OOH}^{-}$aq and $\mathrm{O}_{2 \text { aq }}$, was account $\left(\mathrm{G}_{\text {solvation }}\right)$ by adding the difference in free energy between the gas-phase state and the aqueousphase state. $^{61}$ Zero-point energy (ZPE) corrections were also included based on the calculated vibrational frequencies. For the potential-dependent step involving n-electron transfer, $\Delta \mathrm{G}$ at potential U were shifted by neU with respect to that at zero potential. Finally, in our modeling, the electrolyte was considered $0.1 \mathrm{M} \mathrm{KOH}(\mathrm{pH}=13)$ at room temperature and the free energy was corrected according to previous work. ${ }^{21}$ The binding of an adsorbate should also be affected by the external potential, but the correction was shown to be small according to the previous study. $^{62}$ Therefore, we neglected adsorbate-electric field interactions.

\subsection{Reaction network}

To describe the reaction network for the ORR under alkaline conditions, eleven (11) elementary steps were taken into consideration. Firstly, an $\mathrm{O}_{2}$ molecule is adsorbed on the $\mathrm{Pt}(111)$ surface from the electrolyte,

$$
\mathrm{O}_{2 \mathrm{aq}}+2 * \leftrightarrow * * \mathrm{O}_{2}
$$

The DFT calculations show that $\mathrm{O}_{2}$ prefers to adsorb at the bridge sites on the Pt(111) surface with and without presence of water. Both $2 \mathrm{e}^{-}$and $4 \mathrm{e}^{-}$mechanisms were included for the sequential reduction reactions of $* * \mathrm{O}_{2}$. Along the $4 \mathrm{e}^{-}$pathway, $* * \mathrm{O}_{2}$ is dissociated into $* \mathrm{O}$ at fcc hollow sites (Step 5), and then reduced by $\mathrm{H}_{2} \mathrm{O}_{\text {aq }}$ together with one electron transfer to form * $\mathrm{OH}$ at top sites (Step 6) and a solvated $\mathrm{OH}_{\text {aq }}^{-}$anion. The surface bound ${ }^{*} \mathrm{OH}$ formed in Step 6 dissolves as $\mathrm{OH}_{\text {aq }}^{-}$as result of a direct one electron reduction (Step 7), or by one electron 
reduction with $\mathrm{H}_{2} \mathrm{O}_{\mathrm{aq}}$ (Step 8). This series of reactions is via the so-called dissociative mechanism given below:

$$
\begin{gathered}
* * \mathrm{O}_{2} \leftrightarrow 2 * \mathrm{O} \\
* \mathrm{O}+\mathrm{H}_{2} \mathrm{O}_{\mathrm{aq}}+\mathrm{e}^{-} \leftrightarrow * \mathrm{OH}+\mathrm{OH}_{\mathrm{aq}}^{-} \\
* \mathrm{OH}+\mathrm{e}^{-} \leftrightarrow *+\mathrm{OH}_{\mathrm{aq}}^{-} \\
* \mathrm{OH}+\mathrm{H}_{2} \mathrm{O}_{\mathrm{aq}}+\mathrm{e}^{-} \leftrightarrow * \mathrm{H}_{2} \mathrm{O}+\mathrm{OH}_{\mathrm{aq}}^{-}
\end{gathered}
$$

The second $4 \mathrm{e}^{-}$sequence is via the associative mechanism. ${ }^{21}$ Similar to Step 6 above, the $* * \mathrm{O}_{2}$ is reduced to form ${ }^{* *} \mathrm{OOH}$ at bridge sites via $\mathrm{H}_{2} \mathrm{O}_{\text {aq }}$ and one electron transfer (Step 9). The **OOH product is the precursor for $\mathrm{O}-\mathrm{O}$ bond cleavage, which is driven by a second electron transfer step (step 10).

$$
\begin{gathered}
* * \mathrm{O}_{2}+\mathrm{H}_{2} \mathrm{O}_{\mathrm{aq}}+\mathrm{e}^{-} \leftrightarrow * * \mathrm{OOH}+\mathrm{OH}_{\mathrm{aq}}^{-} \\
* * \mathrm{OOH}+\mathrm{e}^{-} \leftrightarrow * \mathrm{O}+*+\mathrm{OH}_{\mathrm{aq}}^{-}
\end{gathered}
$$

Both the dissociative and associative mechanisms have been widely used to describe the ORR on Pt(111) in acid solution. ${ }^{21,43,44,56,59}$ Each reduction step is potential-dependent, and when mediated by $\mathrm{H}_{2} \mathrm{O}_{\mathrm{aq}}$, the electron transfer step is coupled with the production of $\mathrm{OH}_{\text {aq. }}^{-}$However, water is not only available as $\mathrm{H}_{2} \mathrm{O}_{a q}$ in the electrolyte, but also as adsorbed molecular $* \mathrm{H}_{2} \mathrm{O}$ on the surface, which can also participate in the reduction process. This led us to consider a third pathway for the $4 \mathrm{e}^{-}$mechanism, which we called the “* $\mathrm{H}_{2} \mathrm{O}$-mediated mechanism." Here, chemisorbed ${ }^{*} \mathrm{H}_{2} \mathrm{O}$ rather than aqueous $\mathrm{H}_{2} \mathrm{O}_{\text {aq }}$ is the reagent for the reduction of $* * \mathrm{O}_{2}$ (Step 11), *O (Step 12), and **OOH (Step 13) to *OH, i.e.,

$$
\begin{gathered}
* * \mathrm{O}_{2}+{ }^{*} \mathrm{H}_{2} \mathrm{O} \leftrightarrow * * \mathrm{OOH}+* \mathrm{OH} \\
* \mathrm{O}+* \mathrm{H}_{2} \mathrm{O} \leftrightarrow 2 * \mathrm{OH} \\
* * \mathrm{OOH} \leftrightarrow * \mathrm{O}+* \mathrm{OH} .
\end{gathered}
$$

Steps (11) through (13) only involve the adsorbed species on the surface with no electron transfer, hence, they are potential-independent surface reactions. The only contribution to the current depends on the dissolution of the ${ }^{*} \mathrm{OH}$ produced via Step 7 or Step 8. In addition, the potential-independent dissociation of $* * \mathrm{OOH}$ to $* \mathrm{O}$ and $* \mathrm{OH}$ (Step 13) was also included. The ${ }^{*} \mathrm{H}_{2} \mathrm{O}$-mediated mechanism was not considered in previous mechanistic studies for the ORR on Pt in acidic media, but as demonstrated below, it can be the dominant pathway in alkaline solution. 
Although not likely, ${ }^{63}$ the pathway via a $2 \mathrm{e}^{-}$mechanism was also included as part of the reaction network. In this case, the ${ }^{* *} \mathrm{OOH}$ formed in Step 9 and Step 12 was dissolved directly into the electrolyte as $\mathrm{OOH}_{\text {aq }}^{-}$(Step 14) by the reaction

$$
* * \mathrm{OOH}+\mathrm{e}^{-} \leftrightarrow 2 *+\mathrm{OOH}_{\mathrm{aq}}^{-} .
$$

\subsection{KMC Simulation}

To gain a better understanding of the complex reaction network for the ORR on $\operatorname{Pt}(111)$, we developed a KMC code to simulate a time series of the reaction. A Pt(111) surface model was constructed. For each adsorption site on the surface, the number of species occupied at neighboring sites was counted to account for the coverage and, therefore, coverage-dependent interactions. In the KMC simulation, all possible elementary steps $\mathrm{i}$ and the corresponding rates, $\mathrm{r}_{\mathrm{i}}$, were evaluated, and $\mathrm{q}$ was selected when it satisfied $\sum_{i=1}^{q} r_{i} \geq \rho \times R \geq \sum_{i=1}^{q-1} r_{i}$ according to Monte Carlo method. ${ }^{64-66}$ Here $\mathrm{R}$ is the sum of sequence for all reaction rates and $\rho$ is generated by a random number generator. In order to improve the efficiency of simulation, a binary tree data structure was used. ${ }^{67}$

In our KMC simulation, $r_{i}$ was determined using the Arrhenius equation as $v_{i} \exp \left(E_{a} / k_{b} T\right)$, where $E_{a i}$ is the activation barrier for step i calculated from DFT (see Section 2.1). The preexponential factor, $v$, was set as $10^{13}$ which is typical surface reactions at room temperature and set to $10^{9}$ for potential-dependent reactions involved in the ORR on $\operatorname{Pt}(111)$ according to previous studies. ${ }^{24}$

The external potential range was varied from $0.2 \mathrm{~V}$ to $0.95 \mathrm{~V}$. The corresponding change in current density at each potential was estimated by counting the electron-transfer steps as

$$
\mathrm{j}=\frac{\mathrm{e}}{\mathrm{A}} \sum T O F
$$

where e is the electronic charge for an electron, A is surface area and the TOF is the turnover frequency of reactions involving electron-transfer. In this way, a polarization curve describing the variation of current density could then be calculated, which allowed direct comparison with experimental measurements.

\section{Results and discussion}

\subsection{DFT calculations}




\subsubsection{Effect of water}

Previous studies have shown that it is necessary to include water interactions in order to accurately simulate the mechanism of ORR on Pt(111) in acid solution. ${ }^{35,68-72}$ In these studies, the interfacial water was described by several water molecules, a bilayer (BL) of water with an ice-like structure, or multiple layers of water saturated on the surface. It remains unclear which is the most appropriate way to describe solvation effects at the water-Pt(111) interface. In the present study, our interest is the double-layer region near $\operatorname{Pt}(111)$, which is essential for electrocatalytic ORR in alkaline solution. Based on a recent study using scanning tunneling microscopy (STM), ${ }^{73}$ we chose the ice-like bilayer structure for the present study. It is constructed by a honeycomb $(\sqrt{3} \times \sqrt{3})$ R30 pattern with 2/3 monolayer (ML) of water coverage, where half of water molecules are $* \mathrm{H}_{2} \mathrm{O}$ and the other half has an $\mathrm{O}-\mathrm{H}$ bond pointing down $(\mathrm{H}-$ down), ${ }^{74}$ which is slightly more stable than the H-up structure.

According to our calculations, the effect of water on the binding energies of $* \mathrm{OH}$ and ${ }^{* *} \mathrm{OOH}$ is more significant than that of ${ }^{* *} \mathrm{O}_{2}$ and $* \mathrm{O}$ (see Supporting Information for details) in agreement with previous observations. ${ }^{21,68,72}$ This is due to the abilities of $* \mathrm{OH}$ and $* * \mathrm{OOH}$ to form more hydrogen bonds compared to $* \mathrm{O}$ and $* * \mathrm{O}_{2}$ (Figure 1). In consistent with previous study, ${ }^{75}$ besides binding with a Pt atom on the surface each $\mathrm{H}_{2} \mathrm{O}$ molecule also forms three hydrogen bonds with the surroundings in the water BL. To adsorb a reaction intermediate on the $\operatorname{Pt}(111)$ surface, one of $* \mathrm{H}_{2} \mathrm{O}$ is removed, which results in the loss of three hydrogen bonds and disruption of the ice-like structure. The adsorption of $* \mathrm{OH}$ or $* * \mathrm{OOH}$ not only restores the missing hydrogen bonds and the hexagonal ice-like conformation, but also stabilizes the water layer demonstrated by shorter hydrogen bonds than those in the water BL (Figure 1a, b and see $\mathrm{SI})$. For $* * \mathrm{O}_{2}$, two of the missing hydrogen bonds are recovered and one side of the hexagonal water ring is missing (Figure 1c). In the case of $* \mathrm{O}$, only one hydrogen bond is formed (Figure 1d). Moreover, *O adsorption destabilizes the hexagonal water BL structure by breaking one additional hydrogen bond between water molecules. When the water solvation shell was increased by adding the $2^{\text {nd }}$ and the $3^{\text {rd }} \mathrm{BL}$ of water, much smaller effects on the binding geometries and energetics (Figure S1 and Table S1) were observed as compared to a single BL. Adsorbed intermediates only interact directly with water molecules in the $1^{\text {st }}$ water bilayer via hydrogen bonds, while the contributions from the $2^{\text {nd }}$ and $3^{\text {rd }}$ water bilayers are indirect and much smaller. 
Next we considered how variations in binding energies due to water solvation impact the potential energy diagram of the ORR. To check that, the variations in free energy along the ORRs via the three $4 \mathrm{e}^{-}$mechanisms (Step 5-13) were plotted in Figure 2. Our results show that water solvation clearly affects the energetics of elementary steps involved in the ORR. Including the $1^{\text {st }} \mathrm{BL}$ of water is essential, which makes an obvious difference in the free energy profile for the ORR on Pt(111). Along the dissociative or associative pathways (Figure 2a, b), the presence of water stabilizes $* * \mathrm{OOH}$ and ${ }^{*} \mathrm{OH}$, and facilitates the reduction of ${ }^{*} \mathrm{O}_{2}$ (Step 9) and/or $* \mathrm{O}$ (Step 6); while the removal of ${ }^{*} \mathrm{OH}$ in the form of $\mathrm{OH}_{\text {aq }}^{-}$(Step 7) is more difficult. Similarly for the ORR via the ${ }^{*} \mathrm{H}_{2} \mathrm{O}$-mediated mechanism (Figure $2 \mathrm{c}$ ), ${ }^{*} \mathrm{OH}$ and $* * \mathrm{OOH}$ are stabilized and the reductions of $* * \mathrm{O}_{2}$ (step 11) and $* \mathrm{O}$ (Step 12) are favored due to the interactions with water. The main difference among three mechanisms is observed when the external potential is applied. With potential increasing from $0 \mathrm{~V}$ to $0.9 \mathrm{~V}$ (vs. RHE), the potential-dependent steps involving electron transfers are less favorable in all three mechanisms. The associative mechanism is affected the most, where the ${ }^{* *} \mathrm{OOH}$ and ${ }^{*} \mathrm{OH}$ formation and $* \mathrm{OH}$ removal are hindered. The $* \mathrm{H}_{2} \mathrm{O}$-mediated mechanism is least affected, with only the removal of $* \mathrm{OH}$ becoming less favorable under applied potential compared to that under zero potential, while the energetics of the other potential-independent steps are essentially unchanged. By comparison, the effects of adding the $2^{\text {nd }}$ and $3^{\text {rd }}$ water BL's are much less (Figure 2). Accordingly, the results from the DFT calculations and KMC simulations presented below were performed using Pt(111) covered by one $\mathrm{BL}$ of water to describe the water-Pt(111) interface.

\subsubsection{Effects of $\mathrm{OH}$ species}

According to cyclic voltammetry studies in both acid and alkaline solutions, * $\mathrm{OH}$ species are co-adsorbed on Pt together $\mathrm{H}_{2} \mathrm{O}$ between $0.65 \mathrm{~V}$ and $0.85 \mathrm{~V}$, which are interest for the ORR. ${ }^{39,}{ }^{76}$ In addition, during the $\mathrm{ORR}, * \mathrm{OH}$ species are important reaction intermediates. Various ways have been proposed for the role of $* \mathrm{OH}$ in the ORR in acid solution. Specifically,

* $\mathrm{OH}$ may act as a spectator to block active sites for catalytic reactions on the surface, ${ }^{7,77-78}$ lead to surface oxidation, ${ }^{7}$ or help in stabilizing water molecules and the reaction intermediates via the formation of hydrogen bonds. ${ }^{27,}{ }^{79-81}$ Previous theoretical studies ${ }^{27,}{ }^{80-82}$ suggested the presence of a stable $* \mathrm{OH} / \mathrm{H}_{2} \mathrm{O}$ network occurring at an ${ }^{*} \mathrm{OH}$ coverage of $1 / 3 \mathrm{ML}$, due to the formation of an alternate arrangement of $* \mathrm{OH}$ and $\mathrm{H}_{2} \mathrm{O}$ in a hexagonal pattern. Other studies by 
Nørskov, et al. also discussed the potential effects of $* \mathrm{O}^{21,83}$ and $* \mathrm{OH}^{27,82}$ coverage on the ORR in acid on Pt-based catalysts. For the AFC, the effect of ${ }^{*} \mathrm{OH}$ can be an even more significant than that in acid solution, since ${ }^{*} \mathrm{OH}$ can also be provided from the electrolyte. To account for the effect of $* \mathrm{OH}$ coverage in our calculations, the variation in binding energies of reaction intermediates and $\mathrm{E}_{\mathrm{a}}$ with the increasing $* \mathrm{OH}$ on the surface was determined.

The differential adsorption of $* \mathrm{OH}$ at different coverages on $\mathrm{Pt}(111)$ was calculated, where ${ }^{*} \mathrm{H}_{2} \mathrm{O}$ in the water $\mathrm{BL}$ was sequentially replaced by $* \mathrm{OH}$. The most stable structure at each $\mathrm{OH}$ coverage was used to calculate the adsorption energies of other reaction intermediates. When the * $\mathrm{OH}$ coverage increased up to $1 / 3 \mathrm{ML}$, the number of hydrogen bonds remains the same as that in the $1^{\text {st }}$ water $\mathrm{BL}$, while the number of dangling $\mathrm{O}-\mathrm{H}$ bonds in the water $\mathrm{BL}$ eventually decreases to zero (Figure 3 and Table S2). As a result, the ${ }^{*} \mathrm{OH} / \mathrm{H}_{2} \mathrm{O}$ network is stabilized, which is demonstrated by the transition of the buckled water BL into a flat plane with hydrogen bond lengths shortened by $\sim 0.1 \AA$. These results agree with previous studies, ${ }^{27,81,84-86}$ showing that the saturation coverage of $* \mathrm{OH}$ at the water/Pt(111) interface is $1 / 3 \mathrm{ML}$ (Figure 4a). At this coverage, stabilization in the water BL dominates the energetics. It corresponds to the so-called halfdissociated water network, ${ }^{27}$ where each honeycomb is constructed by three $* \mathrm{H}_{2} \mathrm{O}$ and three ${ }^{*} \mathrm{OH}$ in an alternating arrangement (Figure 3c). Replacing an additional ${ }^{*} \mathrm{H}_{2} \mathrm{O}$ by $* \mathrm{OH}$ leads to a decrease in the number of hydrogen bonds and the differential binding energy of * $\mathrm{OH}$ increases by $0.38 \mathrm{eV}$ (Figure 4a).

Figure 4 shows that the binding energies of all the other adsorbates vary with the ${ }^{*} \mathrm{OH}$ coverage with two distinct trends. For ${ }^{* *} \mathrm{OOH}$ (Figure $4 \mathrm{~b}$ ) and ${ }^{*} \mathrm{O}$ (Figure $4 \mathrm{c}$ ), the variation in binding energies follows similar upside-down volcano-like trends as that of $* \mathrm{OH}$. At low $* \mathrm{OH}$ coverage, the * $\mathrm{OH}$-induced stabilization by the formation of hydrogen bonds helps to hold the water/OH/adsorbate network on the surface. At high coverage, the bindings are weakened, which is determined by the increasing partial oxidation of surface Pt due to the direct interaction with ${ }^{*} \mathrm{OH}$. These results clearly demonstrate that the variation in binding energy does not scale proportionally with increasing $* \mathrm{OH}$ coverage. The exception is $* * \mathrm{O}_{2}$, where the binding energy decreases linearly with increasing $* \mathrm{OH}$ coverage (Figure 4d). The presence of $* \mathrm{OH}$ limits the mobility of ${ }^{*} \mathrm{H}_{2} \mathrm{O}$ via hydrogen bonds, which are not able to approach ${ }^{* *} \mathrm{O}_{2}$ (Figure S2); the resulting hydrogen bonds between ${ }^{* *} \mathrm{O}_{2}$ and ${ }^{*} \mathrm{H}_{2} \mathrm{O}$ are longer and weaker than that without $* \mathrm{OH}$ present. Consequently, the stabilization due to formation hydrogen bonds has a minor effect, 
while the increasing partial oxidation of surface Pt leads to the weakening of the Pt- $\mathrm{O}_{2}$ interaction. Among the reaction intermediates, the binding of $* \mathrm{OH}$ and $* \mathrm{O}$ are more sensitive to ${ }^{*} \mathrm{OH}$ coverage (Figure 4), as their binding energies strongly depend on the stability of the $* \mathrm{OH} / \mathrm{H}_{2} \mathrm{O}$ network.

The variation in $* \mathrm{OH}$ coverage not only affects the binding energies of the reaction intermediates, but also the activation energies $\left(E_{a}\right)$ of the ORR elementary steps which only involve adsorbed species (Step 5 and Steps 11-13). In general, the $E_{a}$ are raised by increasing the coverage of $* \mathrm{OH}$ up to $1 / 3 \mathrm{ML}$ (Figure S3a). That is, all the surface reactions become less favorable. In addition, the variations in $E_{a}$ are strongly correlated with $\Delta G$ of the reaction (Figure $\mathrm{S} 3 \mathrm{~b}$ ). Overall, the linear relationship via $\mathrm{E}_{\mathrm{a}}=a \Delta \mathrm{G}+b$ ( $a$ and $b$ are constants) or BrønstedEvans-Polanyi (BEP) relationship between reaction energy and activation barrier is followed reasonably well, though $a$ and $b$ vary depending on the reaction species. For the steps involving species that are less sensitive to ${ }^{*} \mathrm{OH}$ coverage, e.g. ${ }^{* *} \mathrm{O}_{2}+{ }^{*} \mathrm{H}_{2} \mathrm{O} \rightarrow{ }^{* *} \mathrm{OOH}$, the $\mathrm{E}_{\mathrm{a}}$ vary less significantly than those involving the intermediates that are sensitive to $* \mathrm{OH}$ coverage, e.g. ${ }^{* *} \mathrm{OOH} \rightarrow{ }^{*} \mathrm{O}+{ }^{*} \mathrm{OH}$. For the other steps involving electron transfers, the $\mathrm{E}_{\mathrm{a}}$ are not calculated due to limitations of standard DFT. Overall, the effect of * $\mathrm{OH}$ coverage on the ORR reactions is complicated; it affects the stability of the water $\mathrm{BL}$, the binding energies of adsorbates, and $\mathrm{E}_{\mathrm{a}}$ for the elementary steps. More importantly, the changes in both binding energies and $E_{a}$ with $* \mathrm{OH}$ coverage depend on the species involved in the reactoion. Embedding the dynamic effect of * $\mathrm{OH}$ coverage on the reaction energetics into our KMC program, as shown in Section 3.2, provides a better description of complex ORR than that assuming a fixed coverage of $* \mathrm{OH}$ or $* \mathrm{O}$ to adjust the binding for other reaction intermediates in the previous kinetic study for the ORR in acid. ${ }^{20-21,24,87-88}$ The effect of ${ }^{*} \mathrm{O}$ coverage was not considered here. Our interest in the ORR around working potential, when the amount of *O is still low.

\subsection{KMC simulations}

\subsubsection{Estimation of ORR activity}

The DFT calculations at the water/Pt(111) interface describe the binding structures of the reaction intermediates and thermodynamics of the elementary steps involved in the ORR in alkaline solution; However, the insight into the reaction kinetics is rather limited. To achieve kinetic understanding, the KMC simulations was carried out, where the three $4 \mathrm{e}^{-}$mechanisms 
(dissociative, associative, and ${ }^{*} \mathrm{H}_{2} \mathrm{O}$-mediated) and $2 \mathrm{e}^{-}$mechanism were all included (see Section 2.2). Besides, it also allows for a direct comparison between the calculated and the experimentally observed polarization curves. Thus, our theoretical model to describe the ORR in alkaline solution on Pt(111) can be validated. Finally, it also enables a better understanding of how the different mechanisms interplay under the ORR conditions.

The binding energies of adsorbates (Figure 4) and the $E_{a}$ of the elementary steps (Figure S3a) employed in the KMC simulations were based on the DFT calculations and discussed in the preceding section. Both the forward and backward reactions were taken into considerations. For potential-dependent steps involving electron transfer, the $\mathrm{E}_{\mathrm{a}}$ were estimated using the DFTcalculated and the BEP relationship based on previous studies for the ORR on $\operatorname{Pt}(111),{ }^{27}$ where $a$ $=0.5$ and $b=0.26$ were reported for proton transfer on $\operatorname{Pt}(111)$ in acid solution. To account for the effect of $* \mathrm{OH}$ coverage, a local $* \mathrm{OH}$ coverage calculator was developed in the KMC code. It updated $* \mathrm{OH}$ coverage on the surface at an applied potential, which allowed the $\mathrm{E}_{\mathrm{a}}$ for each elementary step to be corrected accordingly.

In order to estimate the variation in current density with potential, the rate for $\mathrm{O}_{2}$ adsorption from electrolyte to the Pt(111) electrode (Step 4) was determined by fitting the KMC simulated polarization curve to that previously measured for the ORR on $\operatorname{Pt}(111)$ in $0.1 \mathrm{M} \mathrm{KOH}$ (Figure 5). ${ }^{51}$ We note that the adsorption rate is only associated with the diffusion-limited current density at lower potential $(<0.4 \mathrm{~V})$, rather the ORR working potential $(\sim 0.8 \mathrm{~V})$. By fixing the maximum current density to be the experimental value, ${ }^{51}$ the TOF of $\mathrm{O}_{2}$ adsorption was obtained. The BEP coefficients, $a$ and $b$, are related to the kinetic current density at higher potential, which is the key to the performance of ORR catalysts. ${ }^{24}$ According to our results, $a$ controls the curvature of the polarization curve at the on-set potential, while $b$ affects the half-wave potential. By using the values determined for the ORR in acid solution, ${ }^{27}$ the estimated polarization curve reaches well agreement with the experimental observation. Only with a small tuning, $a=0.42$ and $b=0.24$, a finely match can be achieved (Figure 5). Our combined DFT and KMC simulations are able to describe well the measured polarization curve for the ORR on $\operatorname{Pt}(111)$, which capture not only the onset and half-wave potential at high potential region, but also the small variation in current density at low potential region.

\subsubsection{Reaction intermediates}


As shown in the simulation snapshots in Figure 6, the hexagonal ice-like network of water-Pt(111) interface determined by DFT is well reproduced by the KMC matrix. The adsorption sites for each reaction intermediate are located within the hexagonal lattice according to the DFT calculations. The KMC simulations also provided the coverage of the abundant reaction intermediates as a function of applied potential. Below $0.75 \mathrm{~V}$, the surface is mostly covered by water in an ice-like structure (Figure 6). Adsorbed * $\mathrm{OH}$ emerges from $0.75 \mathrm{~V}$ (the green dash line, Figure 5), and accumulates with increasing potential and a rapid decrease in current density. At $0.83 \mathrm{~V}$ (Figure 6), the highly-stable, half-dissociated $* \mathrm{OH} / \mathrm{H}_{2} \mathrm{O}$ network starts to form locally. At $0.95 \mathrm{~V}$, the accumulation of $* \mathrm{OH}$ slows down and reaches a coverage of about 0.23 ML. Starting from about $0.9 \mathrm{~V}, * \mathrm{O}$ appear (yellow dash line, Figure 5) and replace $* \mathrm{OH}$ and $* \mathrm{H}_{2} \mathrm{O}$ due to oxidation at higher potentials (Figure 6). As a result, the ORR comes to an end. The other reaction intermediates are either very small amount (e.g. **OOH) or barely seen (e.g. $* * \mathrm{O}_{2}$ ) over the entire potential range studied. Similar variations in the coverage of surface species during the ORR on Pt(111) were also observed in acid solution. ${ }^{7,24,79}$ In both cases, the ORR slows down at the potential when $* \mathrm{OH}$ start to build up on the surface and eventually stops when the potential is increased to allow the formation of $* \mathrm{O}$.

\subsubsection{Reaction mechanism}

As evidenced by the present KMC results, there is not much difference between the polarization curves and abundant reaction intermediates for the ORR in alkaline and acid solution, in agreement with the experimental observations. ${ }^{89}$ This raises the question as to whether the processes occurring during the ORR in acid solution are the same in alkaline solution. How do the multiple mechanisms interplay during the ORR? To address it, we made use of the ability within our KMC model to count the times that an elementary step occurs during a certain time interval at an applied potential, referred to as "reaction counts" in this paper. This procedure allows us to identify the main steps that occur during the ORR and, therefore, identify the dominant mechanism(s).

The reaction counts for both the potential-dependent (solid lines) and potentialindependent surface reactions (dash lines) are shown in Figure 7. The elementary step with the largest number of reaction counts over the entire potential range studied is ${ }^{*} \mathrm{OH}$ removal as $\mathrm{OH}_{\text {aq }}^{-}$, which is representative of electron transfer during the ORR. Since this step is involved in 
all reaction mechanisms, we cannot specify the preference of each mechanism accordingly. However, different contributions for the other steps are clearly observed. For $* * \mathrm{O}_{2}$ reduction to $* * \mathrm{OOH}$, the potential-independent surface reaction conducted via $* \mathrm{H}_{2} \mathrm{O}$ (Step 11, blue dash line) is more populated than the potential-dependent step (Step 9, blue solid line), which has a reaction count close to zero. Similarly, the $* \mathrm{H}_{2} \mathrm{O}$-mediated surface reaction involving the reduction of $* \mathrm{O}$ to ${ }^{*} \mathrm{OH}$ (Step 13, green dash line) is dominant with no contribution from the corresponding potential-dependent step (step 6, green solid line). For **OOH dissociation, both the potentialindependent (Step 12, yellow dash line) and the potential-dependent steps (Step 10, yellow solid line) help, though the former is more intensive than the latter. The reaction count results clearly show that the ORR on $\mathrm{Pt}(111)$ in alkaline solution mainly follows a $4 \mathrm{e}^{-}$transfer mechanism, with the $* \mathrm{H}_{2} \mathrm{O}$-mediated mechanism dominated. The reduction of $* * \mathrm{O}_{2}$ via $* \mathrm{H}_{2} \mathrm{O}$ rather than $\mathrm{H}_{2} \mathrm{O}_{\mathrm{aq}}$ leads to the formation of $* * \mathrm{OOH}, * \mathrm{O}$ and $* \mathrm{OH}$. During the reduction reactions, there is no electron transfer until the final removal of ${ }^{*} \mathrm{OH}$ from the surface in the form of $\mathrm{OH}_{\mathrm{aq}}^{-}$. In contrast, the contributions from both the associative and dissociative mechanisms, which are proposed for the ORR in acid solution, are much less.

The ORR via the partial $2 \mathrm{e}^{-}$mechanism represented by formation of $\mathrm{OOH}_{\text {aq }}^{-}$only occurs at low potentials ( $<0.4 \mathrm{~V}$, Figure 7 ). When the potential increases, the $\Delta \mathrm{G}$ for $* * \mathrm{OOH}$ removal as $\mathrm{OOH}_{\mathrm{aq}}^{-}$(step 14, red solid line) is positively shifted by eU (Eq.3) and the $\mathrm{E}_{\mathrm{a}}$ increases accordingly. As a result, the corresponding reaction counts decrease to zero when the potential increases over $0.4 \mathrm{~V}$ (Figure 7). The ORR via $2 \mathrm{e}^{-}$mechanism at low potential agrees very well with the experimental observation (Figure 5). Of course, our model is only able to describe the ORR at the potential which $* \mathrm{H}_{2} \mathrm{O}$ is still present on the surface. Specifically, ${ }^{*} \mathrm{H}_{2} \mathrm{O}$ can be fully oxidized to $* \mathrm{O}$ at higher potential, yet it is beyond the interest of the ORR.

\subsubsection{Activity-controlling factors}

On the basis of the results presented above, we now consider which parameters are most important in determining ORR activity of $\mathrm{Pt}(111)$ in alkaline solution. This topic has been extensively studied in acid solutions, where either the $* \mathrm{O}^{21,83,88,90-92}$ or $* \mathrm{OH}$ binding energy ${ }^{24}$, 87-88, 93 are selected as a descriptor to capture the difference in the ORR activity of one catalyst to the next. The strong $\mathrm{O} / \mathrm{OH}-\mathrm{Pt}(111)$ interaction can make proton and electron transfer to *O or * $\mathrm{OH}$ very difficult, which is the major cause for the high overpotential” of the ORR in acid 
solution. Slightly weaker binding, $\sim 0.2 \mathrm{eV}$ for ${ }^{*} \mathrm{O}$ or $\sim 0.1 \mathrm{eV}$ for ${ }^{*} \mathrm{OH}$, is predicted to promote the ORR activity of Pt, though over-weakening should also be avoided to allow the facile formation of $* \mathrm{OOH}^{21,87,93}$

In the present study, sensitivity analyses were carried out, where each parameter in the KMC model was shifted by a small amount from its original value and the other parameters were kept constant. ${ }^{94-96}$ Such analyses enable the identification of the key steps that control the activity. Here, we shifted the binding energy of each reaction intermediate by less than $0.2 \mathrm{eV}$, which in turn varied $\Delta \mathrm{G}$. For the steps involving electron transfers, the $\mathrm{E}_{\mathrm{a}}$ was estimated according to the BEP relationship as indicated Section 3.2.1. For the potential-independent surface reactions, $E_{a}$ was determined based on the established relationship between $\Delta \mathrm{G}$ and $\mathrm{E}_{\mathrm{a}}$ for each step (Figure S3b). Two intermediates, ${ }^{* *} \mathrm{O}_{2}$ and $* \mathrm{OH}$, were found to change the profile of the polarization curve significantly with small shifts $(<0.2 \mathrm{eV})$ in binding energy. Variations in the binding of ${ }^{* *} \mathrm{O}_{2}$ affect the initial current density, rather than the onset potential. When the $\mathrm{Pt}-\mathrm{O}_{2}$ interaction is decreased by $0.2 \mathrm{eV}$, a reduction in the current density $\left(\sim 4 \mathrm{~mA} / \mathrm{cm}^{2}\right.$, Figure $\left.8 a\right)$ is observed. Such weakening limits the sticking of $\mathrm{O}_{2}$ on the surface and therefore the ORR activity. When decreasing the ${ }^{* *} \mathrm{O}_{2}$ binding energy by less than $0.2 \mathrm{eV}$ or increasing the binding up to $0.2 \mathrm{eV}$, the $\mathrm{O}_{2}$ adsorption is no longer the activity-controlling step and no obvious change in polarization curve is observed. By comparison, the effect of $* \mathrm{OH}$ binding on the shift of polarization curve is much more significant, which in particular affects the onset potential. If the ${ }^{*} \mathrm{OH}$ binding is weakened by only $0.1 \mathrm{eV}$, the onset is shifted to higher potential by $0.1 \mathrm{~V}$, while the strengthened ${ }^{*} \mathrm{OH}$ binding by $0.1 \mathrm{eV}$ leads to a decreased onset by $0.1 \mathrm{~V}$ (Figure 8b). Such a small variation in ${ }^{*} \mathrm{OH}$ binding energy $(0.1 \mathrm{eV})$ affects only the current-contributing step, ${ }^{*} \mathrm{OH}$ removal, along the dominant $* \mathrm{H}_{2} \mathrm{O}$-mediated mechanism. Consequently, the polarization curve responds the most sensitively to the ${ }^{*} \mathrm{OH}$ binding energy. Overall, the sensitivity analysis indicates that to facilitate the ORR activity of $\operatorname{Pt}(111)$ in alkaline solution, a good promoter should be able to weaken $\mathrm{Pt}-\mathrm{OH}$ binding and accelerate ${ }^{*} \mathrm{OH}$ removal, while still allowing the stabilization and reaction of $* * \mathrm{O}_{2}$. Ideally, the binding of $* \mathrm{OH}$ and ${ }^{* *} \mathrm{O}_{2}$ should be tuned differently; weakening $\mathrm{OH}$ binding should be accompanied with a small weakening or a strengthening in ${ }^{* *} \mathrm{O}_{2}$ binding. For catalysts which only have one kind of active sites on the surface, ${ }^{*} \mathrm{OH}$ and ${ }^{* *} \mathrm{O}_{2}$ binding always vary together, e.g., comparing one metal surface to the 
next. ${ }^{21}$ As an alternative, multifunctional catalysts might be able to provide various active sites that allow heterogeneous tuning of $* \mathrm{OH}$ and ${ }^{* *} \mathrm{O}_{2}$ binding.

\section{Conclusion}

Combined DFT calculations and KMC simulations were performed to understand the mechanism of the ORR on $\mathrm{Pt}(111)$ in alkaline solution. Our KMC simulations based on extensive DFT calculations allowed well description of the experimentally measured polarization curve from $0.20 \mathrm{~V}$ to $0.95 \mathrm{~V}$ with basically only one fitting parameter associated with the performance at low potential $(<0.4 \mathrm{~V})$. At the mechanistic level, the calculations also revealed several aspects of the surface chemistry which strongly impact the ORR kinetics on Pt in alkaline solutions. Firstly, our results show that the inclusion of water is necessary for predictive modeling. The intermediates involved in the ORR are stabilized to different extents by interacting with environmental water molecules via hydrogen bonds. One bilayer of water is found to be a good compromise; specifically, one bilayer is able to provide sufficient water molecules to describe solvation effects close to the surface with reasonable computational cost. Secondly, we find that the $* \mathrm{OH}$ coverage, the most abundant intermediate on the surface, strongly impacts the binding of other intermediates and therefore, the ORR rate. Thirdly, chemisorbed ${ }^{*} \mathrm{H}_{2} \mathrm{O}$ on the surface is essential as it acts as the reducing agent for ${ }^{*} \mathrm{O}_{2}$ and ${ }^{*} \mathrm{O}$. The ${ }^{*} \mathrm{H}_{2} \mathrm{O}$-mediated $4 \mathrm{e}^{-}$transfer mechanism, which dominates the overall ORR, involves mostly potential-independent surface reactions with only the final removal of * $\mathrm{OH}$ from the surface as $\mathrm{OH}_{\text {aq }}^{-}$contributing to the current. By comparison, the contributions from other $4 \mathrm{e}^{-}$transfer mechanisms (associative and dissociative), which are typically used to describe the ORR in acid solution, as well as the $2 \mathrm{e}^{-}$transfer mechanism only at low potential $(<0.4 \mathrm{~V})$ are much less. Finally, sensitivity analyses show that the binding of ${ }^{*} \mathrm{OH}$ and ${ }^{* *} \mathrm{O}_{2}$ are the key factors to tune the ORR activity on Pt(111). A good promoter should be able to weaken the Pt-OH bond and prevent the buildup of $* \mathrm{OH}$, while still interacting with $\mathrm{O}_{2}$ well enough to enable the ORR. The results of this study not only provide a mechanistic foundation for understanding experimental observations of ORR on Pt in alkaline solution, but also offer specific guidance for future optimization of ORR catalysts. 
Supporting Information. Details of binding geometries and binding energies of reaction intermediates as well as reaction free energies and activation barriers of elementary steps involved in the ORR at water/Pt(111) interface. This material is available free of charge via the Internet at http://pubs.acs.org.

\section{Acknowledgement}

The research was carried out at Brookhaven National Laboratory under contract DESC0012704 with the US Department of Energy, Division of Chemical Sciences. The DFT calculations were performed using computational resources at the Center for Functional Nanomaterials, a user facility at Brookhaven National Laboratory, and at the National Energy Research Scientific Computing Center (NERSC), which is supported by the Office of Science of the U.S. DOE under Contract No. DE-AC02-05CH11231.

\section{References}

1. Varcoe, J. R.; Slade, R. C. T., Prospects for Alkaline Anion-Exchange Membranes in Low Temperature Fuel Cells. Fuel Cells 2005, 5, 187-200.

2. Varcoe, J. R.; Slade, R. C. T.; Wright, G. L.; Chen, Y., Steady-State Dc and Impedance Investigations of $\mathrm{H}_{2} / \mathrm{O}_{2}$ Alkaline Membrane Fuel Cells with Commercial $\mathrm{Pt} / \mathrm{C}, \mathrm{Ag} / \mathrm{C}$, and $\mathrm{Au} / \mathrm{C}$ Cathodes. J. Phys. Chem. B 2006, 110, 21041-21049.

3. Adams, L. A.; Poynton, S. D.; Tamain, C.; Slade, R. C.; Varcoe, J. R., A Carbon Dioxide Tolerant Aqueous - Electrolyte - Free Anion - Exchange Membrane Alkaline Fuel Cell. ChemSusChem 2008, 1, 79-81.

4. ANASTASIJEVIC, N.; VESOVIC, V.; ADZIC, R., Determination of the Kinetic-Parameters of the Oxygen Reduction Reaction Using the Rotating-Ring-Disk Electrode .1. Theory. J. Electroanal. Chem. 1987, 229, 305-316.

5. Wang, J. X.; Zhang, J.; Adzic, R. R., Double-Trap Kinetic Equation for the Oxygen Reduction Reaction on Pt(111) in Acidic Media. J. Phys. Chem. A 2007, 111, 12702-12710.

6. Shao, M.-h.; Liu, P.; Adzic, R. R., Superoxide Anion Is the Intermediate in the Oxygen Reduction Reaction on Platinum Electrodes. J. Am. Chem. Soc. 2006, 128, 7408-7409.

7. Wang, J. X.; Markovic, N. M.; Adzic, R. R., Kinetic Analysis of Oxygen Reduction on Pt(111) in Acid Solutions: Intrinsic Kinetic Parameters and Anion Adsorption Effects. J. Phys. Chem. B 2004, 108, 4127-4133.

8. Lee, S. W.; Chen, S.; Suntivich, J.; Sasaki, K.; Adzic, R. R.; Shao-Horn, Y., Role of Surface Steps of Pt Nanoparticles on the Electrochemical Activity for Oxygen Reduction. J. Phys. Chem. Lett. 2010, 1, 1316-1320. 
9. Marković, N. M.; Adžić, R. R.; Cahan, B. D.; Yeager, E. B., Structural Effects in Electrocatalysis: Oxygen Reduction on Platinum Low Index Single-Crystal Surfaces in Perchloric Acid Solutions. J. Electroanal. Chem. 1994, 377, 249-259.

10. Zhang, J.; Vukmirovic, M.; Xu, Y.; Mavrikakis, M.; Adzic, R., Controlling the Catalytic Activity of Platinum-Monolayer Electrocatalysts for Oxygen Reduction with Different Substrates. Angew. Chem. Int. Ed. 2005, 44, 2132-2135.

11. Fernández, J. L.; Bard, A. J., Scanning Electrochemical Microscopy. 47. Imaging Electrocatalytic Activity for Oxygen Reduction in an Acidic Medium by the Tip Generation Substrate Collection Mode. Anal. Chem. 2003, 75, 2967-2974.

12. Stephens, I. E. L., et al., Tuning the Activity of Pt(111) for Oxygen Electroreduction by Subsurface Alloying. J. Am. Chem. Soc. 2011, 133, 5485-5491.

13. Wakisaka, M.; Udagawa, Y.; Suzuki, H.; Uchida, H.; Watanabe, M., Structural Effects on the Surface Oxidation Processes at Pt Single-Crystal Electrodes Studied by X-Ray Photoelectron Spectroscopy. Energy Environ. Sci. 2011, 4, 1662-1666.

14. Wakisaka, M.; Suzuki, H.; Mitsui, S.; Uchida, H.; Watanabe, M., Identification and Quantification of Oxygen Species Adsorbed on Pt(111) Single-Crystal and Polycrystalline Pt Electrodes by Photoelectron Spectroscopy. Langmuir 2009, 25, 1897-1900.

15. Markoví, N. M.; Ross Jr, P. N., Surface Science Studies of Model Fuel Cell Electrocatalysts. Surf. Sci. Rep. 2002, 45, 117-229.

16. Climent, V.; Gómez, R.; Orts, J. M.; Feliu, J. M., Thermodynamic Analysis of the Temperature Dependence of $\mathrm{OH}$ Adsorption on $\mathrm{Pt}(111)$ and $\mathrm{Pt}(100)$ Electrodes in Acidic Media in the Absence of Specific Anion Adsorption. J. Phys. Chem. B 2006, 110, 11344-11351.

17. Kuzume, A.; Herrero, E.; Feliu, J. M., Oxygen Reduction on Stepped Platinum Surfaces in Acidic Media. J. Electroanal. Chem. 2007, 599, 333-343.

18. Maciá, M. D.; Campiña, J. M.; Herrero, E.; Feliu, J. M., On the Kinetics of Oxygen Reduction on Platinum Stepped Surfaces in Acidic Media. J. Electroanal. Chem. 2004, 564, 141150.

19. Damjanovic, A.; Genshaw, M. A.; Bockris, J. O. M., The Mechanism of Oxygen Reduction at Platinum in Alkaline Solutions with Special Reference to $\mathrm{H}_{2} \mathrm{O}_{2}$. J. Electrochem. Soc. 1967, 114.

20. Casalongue, H. S.; Kaya, S.; Viswanathan, V.; Miller, D. J.; Friebel, D.; Hansen, H. A.; Nørskov, J. K.; Nilsson, A.; Ogasawara, H., Direct Observation of the Oxygenated Species During Oxygen Reduction on a Platinum Fuel Cell Cathode. Nat. Commun. 2013, 4.

21. Norskov, J.; Rossmeisl, J.; Logadottir, A.; Lindqvist, L.; Kitchin, J.; Bligaard, T.; Jonsson, H., Origin of the Overpotential for Oxygen Reduction at a Fuel-Cell Cathode. J. Phys. Chem. B 2004, 108, 17886-17892.

22. Calvo, S. R.; Balbuena, P. B., Theoretical Analysis of Reactivity on Pt (111) and Pt-Pd (111) Alloys. Surf. Sci. 2007, 601, 4786-4792.

23. Jacob, T., The Mechanism of Forming $\mathrm{H}_{2} \mathrm{O}$ from $\mathrm{H}_{2}$ and $\mathrm{O}_{2}$ over a Pt Catalyst Via Direct Oxygen Reduction. Fuel Cells 2006, 6, 159-181.

24. Hansen, H. A.; Viswanathan, V.; Norskov, J. K., Unifying Kinetic and Thermodynamic Analysis of $2 \mathrm{e}^{-}$and $4 \mathrm{e}^{-}$Reduction of Oxygen on Metal Surfaces. J. Phys. Chem. C 2014, 118, 6706-6718. 
25. Miller, D. J.; Oberg, H.; Naslund, L. A.; Anniyev, T.; Ogasawara, H.; Pettersson, L. G. M.; Nilsson, A., Low $\mathrm{O}_{2}$ Dissociation Barrier on Pt(111) Due to Adsorbate-Adsorbate Interactions. J. Chem. Phys. 2010, 133.

26. McEwen, J. S.; Bray, J. M.; Wu, C.; Schneider, W. F., How Low Can You Go? Minimum Energy Pathways for $\mathrm{O}_{2}$ Dissociation on Pt(111). Phys. Chem. Chem. Phys. 2012, 14, 1667716685.

27. Tripković, V.; Skúlason, E.; Siahrostami, S.; Nørskov, J. K.; Rossmeisl, J., The Oxygen Reduction Reaction Mechanism on Pt (111) from Density Functional Theory Calculations. Electrochim. Acta 2010, 55, 7975-7981.

28. Keith, J. A.; Jerkiewicz, G.; Jacob, T., Theoretical Investigations of the Oxygen Reduction Reaction on Pt(111). ChemPhysChem 2010, 11, 2779-2794.

29. Nilekar, A. U.; Mavrikakis, M., Improved Oxygen Reduction Reactivity of Platinum Monolayers on Transition Metal Surfaces. Surf. Sci. 2008, 602, L89-L94.

30. Keith, J. A.; Jacob, T., Theoretical Studies of Potential-Dependent and Competing Mechanisms of the Electrocatalytic Oxygen Reduction Reaction on Pt(111). Angew. Chem. Int. Ed. 2010, 49, 9521-9525.

31. Anderson, A. B.; Uddin, J.; Jinnouchi, R., Solvation and Zero-Point-Energy Effects on $\mathrm{OH}(\mathrm{Ads})$ Reduction on Pt(111) Electrodes. J. Phys. Chem. C 2010, 114, 14946-14952.

32. Anderson, A. B., $\mathrm{O}_{2}$ Reduction and $\mathrm{CO}$ Oxidation at the Pt-Electrolyte Interface. The Role of $\mathrm{H}_{2} \mathrm{O}$ and $\mathrm{OH}$ Adsorption Bond Strengths. Electrochim. Acta 2002, 47, 3759-3763.

33. Janik, M. J.; Taylor, C. D.; Neurock, M., First-Principles Analysis of the Initial Electroreduction Steps of Oxygen over Pt(111). J. Electrochem. Soc. 2009, 156, B126-B135.

34. Fang, Y.; Wei, G.; Liu, Z., Theoretical Modeling of Electrode/Electrolyte Interface from First-Principles Periodic Continuum Solvation Method. Catal. Today 2013, 202, 98-104.

35. Yeh, K. Y.; Wasileski, S. A.; Janik, M. J., Electronic Structure Models of Oxygen Adsorption at the Solvated, Electrified Pt(111) Interface. Phys. Chem. Chem. Phys. 2009, 11, 10108-10117.

36. Benedikt, U.; Schneider, W.; Auer, A., Modelling Electrified Interfaces in Quantum Chemistry: Constant Charge Vs. Constant Potential. Phys. Chem. Chem. Phys. 2013, 15, 27122724.

37. Vlcek, A.; Zalis, S., Modeling of Charge-Transfer Transitions and Excited States in D(6) Transition Metal Complexes by DFT Techniques. Coord. Chem. Rev. 2007, 251, 258-287.

38. Rossmeisl, J.; Skulason, E.; Bjorketun, M. E.; Tripkovic, V.; Norskov, J. K., Modeling the Electrified Solid-Liquid Interface. Chem. Phys. Lett. 2008, 466, 68-71.

39. Ramaswamy, N.; Mukerjee, S., Fundamental Mechanistic Understanding of Electrocatalysis of Oxygen Reduction on Pt and Non-Pt Surfaces: Acid Versus Alkaline Media. Adv. Phys. Chem. 2012, 2012.

40. Appleby, A. J., An International Journal Devoted to All Aspects of Electrode Kinetics, Interfacial Structure, Properties of Electrolytes, Colloid and Biological Electrochemistryelectrocatalysis of Aqueous Dioxygen Reduction. J. Electroanal. Chem. 1993, 357, 117-179.

41. Ramaswamy, N.; Mukerjee, S., Influence of Inner- and Outer-Sphere Electron Transfer Mechanisms During Electrocatalysis of Oxygen Reduction in Alkaline Media. J. Phys. Chem. C 2011, 115, 18015-18026.

42. Adzic, R., Frontiers in Electrochemistry. ELECTROCATALYSIS 1998, 5, 197. 
43. Sepa, D. B.; Vojnovic, M. V.; Damjanovic, A., Kinetics and Mechanism of $\mathrm{O}_{2}$ Reduction at Pt in Alkaline Solutions. Electrochim. Acta 1980, 25, 1491-1496.

44. Rizo, R.; Herrero, E.; Feliu, J., Oxygen Reduction Reaction on Stepped Platinum Surfaces in Alkaline Media. Phys. Chem. Chem. Phys. 2013, 15, 15416-15425.

45. Holewinski, A.; Idrobo, J.-C.; Linic, S., High-Performance Ag-Co Alloy Catalysts for Electrochemical Oxygen Reduction. Nat. Chem. 2014, 6, 828-834.

46. Spendelow, J. S.; Wieckowski, A., Electrocatalysis of Oxygen Reduction and Small Alcohol Oxidation in Alkaline Media. Phys. Chem. Chem. Phys. 2007, 9, 2654-2675.

47. Schmidt, T.; Stamenkovic, V.; Ross Jr, P.; Markovic, N., Temperature Dependent Surface Electrochemistry on Pt Single Crystals in Alkaline Electrolyte Part 3. The Oxygen Reduction Reaction. Phys. Chem. Chem. Phys. 2003, 5, 400-406.

48. Schmidt, T. J.; Stamenkovic, V.; Arenz, M.; Markovic, N. M.; Ross Jr, P. N., Oxygen Electrocatalysis in Alkaline Electrolyte: $\mathrm{Pt}(\mathrm{Hkl}), \mathrm{Au}(\mathrm{Hkl})$ and the Effect of Pd-Modification. Electrochim. Acta 2002, 47, 3765-3776.

49. Viswanathan, V.; Wang, F. Y. F., Theoretical Analysis of the Effect of Particle Size and Support on the Kinetics of Oxygen Reduction Reaction on Platinum Nanoparticles. Nanoscale 2012, 4, 5110-5117.

50. Perez-Alonso, F. J.; McCarthy, D. N.; Nierhoff, A.; Hernandez-Fernandez, P.; Strebel, C.; Stephens, I. E. L.; Nielsen, J. H.; Chorkendorff, I., The Effect of Size on the Oxygen Electroreduction Activity of Mass-Selected Platinum Nanoparticles. Angew. Chem. Int. Ed. 2012, 51, 4641-4643.

51. Lima, F. H. B.; Zhang, J.; Shao, M. H.; Sasaki, K.; Vukmirovic, M. B.; Ticianelli, E. A.; Adzic, R. R., Catalytic Activity-D-Band Center Correlation for the $\mathrm{O}_{2}$ Reduction Reaction on Platinum in Alkaline Solutions. J. Phys. Chem. C 2007, 111, 404-410.

52. Kresse, G.; Furthmüller, J., Efficient Iterative Schemes for Ab Initio Total-Energy Calculations Using a Plane-Wave Basis Set. Phys. Rev. B 1996, 54, 11169.

53. Kresse, G.; Furthmüller, J., Efficiency of Ab-Initio Total Energy Calculations for Metals and Semiconductors Using a Plane-Wave Basis Set. Comput. Mater. Sci. 1996, 6, 15-50.

54. Kresse, G.; Hafner, J., Ab Initio Molecular Dynamics for Liquid Metals. Phys. Rev. B 1993, $47,558$.

55. Kresse, G.; Hafner, J., Ab Initio Molecular Dynamics for Open-Shell Transition Metals. Phys. Rev. B 1993, 48, 13115.

56. Kresse, G.; Hafner, J., Ab Initio Molecular-Dynamics Simulation of the Liquid-MetalAmorphous-Semiconductor Transition in Germanium. Phys. Rev. B 1994, 49, 14251.

57. Blöchl, P. E., Projector Augmented-Wave Method. Phys. Rev. B 1994, 50, 17953.

58. Kresse, G.; Joubert, D., From Ultrasoft Pseudopotentials to the Projector AugmentedWave Method. Phys. Rev. B 1999, 59, 1758-1775.

59. Monkhorst, H. J.; Pack, J. D., Special Points for Brillouin-Zone Integrations. Phys. Rev. B 1976, 13, 5188.

60. Henkelman, G.; Uberuaga, B. P.; Jonsson, H., A Climbing Image Nudged Elastic Band Method for Finding Saddle Points and Minimum Energy Paths. J. Chem. Phys. 2000, 113, 99019904.

61. Dean, J. A. Lange's Handbook of Chemistry; McGraw-Hill: New York, 1985. 
62. Hyman, M. P.; Medlin, J. W., Theoretical Study of the Adsorption and Dissociation of Oxygen on Pt(111) in the Presence of Homogeneous Electric Fields. J. Phys. Chem. B 2005, 109, 6304-6310.

63. Bard, A. J.; Stratmann, M.; Gileadi, E.; Urbakh, M., Thermodynamics and Electrified Interfaces. 2002.

64. Gillespie, D. T., A General Method for Numerically Simulating the Stochastic Time Evolution of Coupled Chemical Reactions. J. Comput. Phys. 1976, 22, 403-434.

65. Voter, A. F., Introduction to the Kinetic Monte Carlo Method. In Radiation Effects in Solids, Springer: 2007; pp 1-23.

66. Fichthorn, K. A.; Weinberg, W. H., Theoretical Foundations of Dynamical Monte Carlo Simulations. J. Chem. Phys. 1991, 95, 1090-1096.

67. Blue, J. L.; Beichl, I.; Sullivan, F., Faster Monte Carlo Simulations. Phys. Rev. E 1995, 51, R867.

68. Rossmeisl, J.; Nørskov, J. K.; Taylor, C. D.; Janik, M. J.; Neurock, M., Calculated Phase Diagrams for the Electrochemical Oxidation and Reduction of Water over Pt(111). J. Phys. Chem. B 2006, 110, 21833-21839.

69. Meng, S.; Wang, E.; Gao, S., Water Adsorption on Metal Surfaces: A General Picture from Density Functional Theory Studies. Phys. Rev. B 2004, 69, 195404.

70. Gu, Z.; Balbuena, P. B., Chemical Environment Effects on the Atomic Oxygen Absorption into Pt(111) Subsurfaces. J. Phys. Chem. C 2007, 111, 17388-17396.

71. Eslamibidgoli, M. J.; Eikerling, M. H., Electrochemical Formation of Reactive Oxygen Species at Pt (111) - a Density Functional Theory Study. ACS Catal. 2015, 5, 6090-6098.

72. Walch, S. P., Effect of Solvation on the Oxygen Reduction Reaction on Pt Catalyst. J. Phys. Chem. C 2011, 115, 7377-7391.

73. Maier, S.; Lechner, B. A. J.; Somorjai, G. A.; Salmeron, M., Growth and Structure of the First Layers of Ice on Ru(0001) and Pt(111). J. Am. Chem. Soc. 2016, 138, 3145-3151.

74. Ogasawara, H.; Brena, B.; Nordlund, D.; Nyberg, M.; Pelmenschikov, A.; Pettersson, L.; Nilsson, A., Structure and Bonding of Water on Pt (111). Phys. Rev. Lett. 2002, 89, 276102.

75. Schiros, T.; Takahashi, O.; Andersson, K. J.; Öström, H.; Pettersson, L. G. M.; Nilsson, A.; Ogasawara, H., The Role of Substrate Electrons in the Wetting of a Metal Surface. J. Chem. Phys. 2010, 132, 094701.

76. Viswanathan, V.; Hansen, H. A.; Rossmeisl, J.; Jaramillo, T. F.; Pitsch, H.; Nørskov, J. K., Simulating Linear Sweep Voltammetry from First-Principles: Application to Electrochemical Oxidation of Water on Pt(111) and Pt 3ni(111). J. Phys. Chem. C 2012, 116, 4698-4704.

77. Li, M. F.; Liao, L. W.; Yuan, D. F.; Mei, D.; Chen, Y. X., PH Effect on Oxygen Reduction Reaction at Pt(111) Electrode. Electrochim. Acta 2013, 110, 780-789.

78. Roques, J.; Anderson, A. B.; Murthi, V. S.; Mukerjee, S., Potential Shift for OH (Ads) Formation on the Pt Skin on Pt3Co (111) Electrodes in Acid Theory and Experiment. J. Electrochem. Soc. 2005, 152, E193-E199.

79. Bondarenko, A. S.; Stephens, I. E. L.; Hansen, H. A.; Pérez-Alonso, F. J.; Tripkovic, V.; Johansson, T. P.; Rossmeisl, J.; Nørskov, J. K.; Chorkendorff, I., The Pt(111)/Electrolyte Interface under Oxygen Reduction Reaction Conditions: An Electrochemical Impedance Spectroscopy Study. Langmuir 2011, 27, 2058-2066. 
80. Karlberg, G.; Wahnström, G., Density-Functional Based Modeling of the Intermediate in the Water Production Reaction on Pt (111). Phys. Rev. Lett. 2004, 92, 136103.

81. Karlberg, G. S.; Wahnström, G., An Interaction Model for $\mathrm{Oh}+\mathrm{H} 2 \mathrm{O}-$ Mixed and Pure H2O Overlayers Adsorbed on Pt(111). J. Chem. Phys. 2005, 122.

82. Hansen, H. A.; Rossmeisl, J.; Nørskov, J. K., Surface Pourbaix Diagrams and Oxygen Reduction Activity of Pt, Ag and Ni (111) Surfaces Studied by Dft. Phys. Chem. Chem. Phys. 2008, 10, 3722-3730.

83. Rossmeisl, J.; Logadottir, A.; Nørskov, J. K., Electrolysis of Water on (Oxidized) Metal Surfaces. Chem. Phys. 2005, 319, 178-184.

84. Clay, C.; Haq, S.; Hodgson, A., Hydrogen Bonding in Mixed $\mathrm{OH}+\mathrm{H}_{2} \mathrm{O}$ Overlayers on Pt (111). Phys. Rev. Lett. 2004, 92, 046102.

85. Schiros, T.; Näslund, L. Å.; Andersson, K.; Gyllenpalm, J.; Karlberg, G. S.; Odelius, M.; Ogasawara, H.; Pettersson, L. G. M.; Nilsson, A., Structure and Bonding of the Water-Hydroxyl Mixed Phase on Pt(111). J. Phys. Chem. C 2007, 111, 15003-15012.

86. Schiros, T.; Ogasawara, H.; Näslund, L. Å.; Andersson, K. J.; Ren, J.; Meng, S.; Karlberg, G. S.; Odelius, M.; Nilsson, A.; Pettersson, L. G. M., Cooperativity in Surface Bonding and Hydrogen Bonding of Water and Hydroxyl at Metal Surfaces. J. Phys. Chem. C 2010, 114, 10240-10248.

87. Viswanathan, V.; Hansen, H. A.; Rossmeisl, J.; Norskov, J. K., Universality in Oxygen Reduction Electrocatalysis on Metal Surfaces. ACS Catal. 2012, 2, 1654-1660.

88. Rossmeisl, J.; Karlberg, G. S.; Jaramillo, T.; Nørskov, J. K., Steady State Oxygen Reduction and Cyclic Voltammetry. Faraday Discuss. 2008, 140, 337-346.

89. Gómez-Marín, A. M.; Rizo, R.; Feliu, J. M., Some Reflections on the Understanding of the Oxygen Reduction Reaction at Pt(111). Beilstein J. Nanotechnol. 2013, 4, 956-967.

90. Jackson, A.; Viswanathan, V.; Forman, A. J.; Larsen, A. H.; Nørskov, J. K.; Jaramillo, T. F., Climbing the Activity Volcano: Core-Shell Ru@Pt Electrocatalysts for Oxygen Reduction. ChemElectroChem 2014, 1, 67-71.

91. Yang, L.; Vukmirovic, M. B.; Su, D.; Sasaki, K.; Herron, J. A.; Mavrikakis, M.; Liao, S.; Adzic, R. R., Tuning the Catalytic Activity of Ru@Pt Core-Shell Nanoparticles for the Oxygen Reduction Reaction by Varying the Shell Thickness. J. Phys. Chem. C 2013, 117, 1748-1753.

92. Jinnouchi, R.; Kodama, K.; Hatanaka, T.; Morimoto, Y., First Principles Based Mean Field Model for Oxygen Reduction Reaction. Phys. Chem. Chem. Phys. 2011, 13, 21070-21083.

93. Stephens, I. E. L.; Bondarenko, A. S.; Gronbjerg, U.; Rossmeisl, J.; Chorkendorff, I., Understanding the Electrocatalysis of Oxygen Reduction on Platinum and Its Alloys. Energy Environ. Sci. 2012, 5, 6744-6762.

94. Choi, Y.; Liu, P., Mechanism of Ethanol Synthesis from Syngas on Rh(111). J. Am. Chem. Soc. 2009, 131, 13054-13061.

95. Yang, Y.; White, M. G.; Liu, P., Theoretical Study of Methanol Synthesis from $\mathrm{CO}_{2}$ Hydrogenation on Metal-Doped Cu(111) Surfaces. J. Phys. Chem. C 2012, 116, 248-256.

96. Kattel, S.; Yan, B.; Chen, J. G.; Liu, P., $\mathrm{CO}_{2}$ Hydrogenation on Pt, Pt/SiO 2 and $\mathrm{Pt} / \mathrm{TiO}_{2}$ : Importance of Synergy between Pt and Oxide Support. J. Catal. 2016. 
Figure and Caption
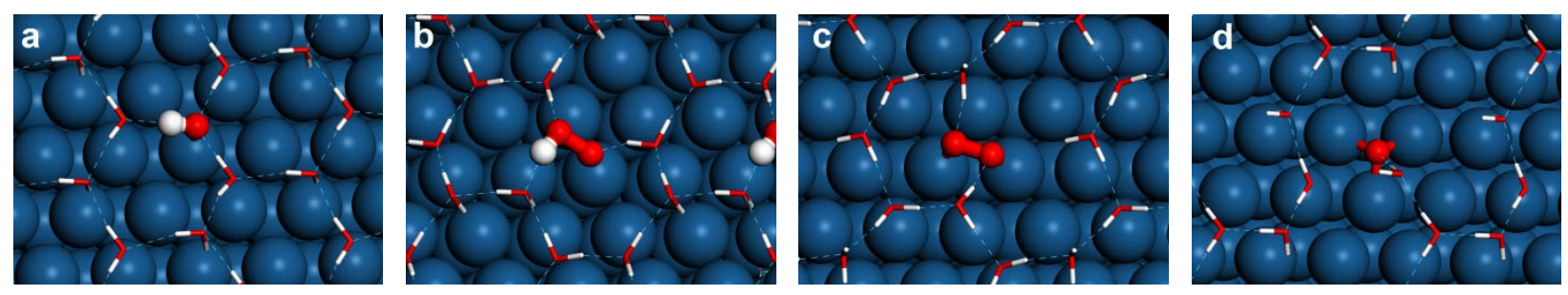

Figure 1. Optimized structures for the adsorption of reaction intermediates, (a) *OH; (b) **OOH; (c) ${ }^{* *} \mathrm{O}_{2}$; (d) $* \mathrm{O}$ on $\mathrm{Pt}(111)$ covered by $1 \mathrm{BL}$ of water (Blue: Pt; red: O; white: O; dashed blue lines: hydrogen bond). 

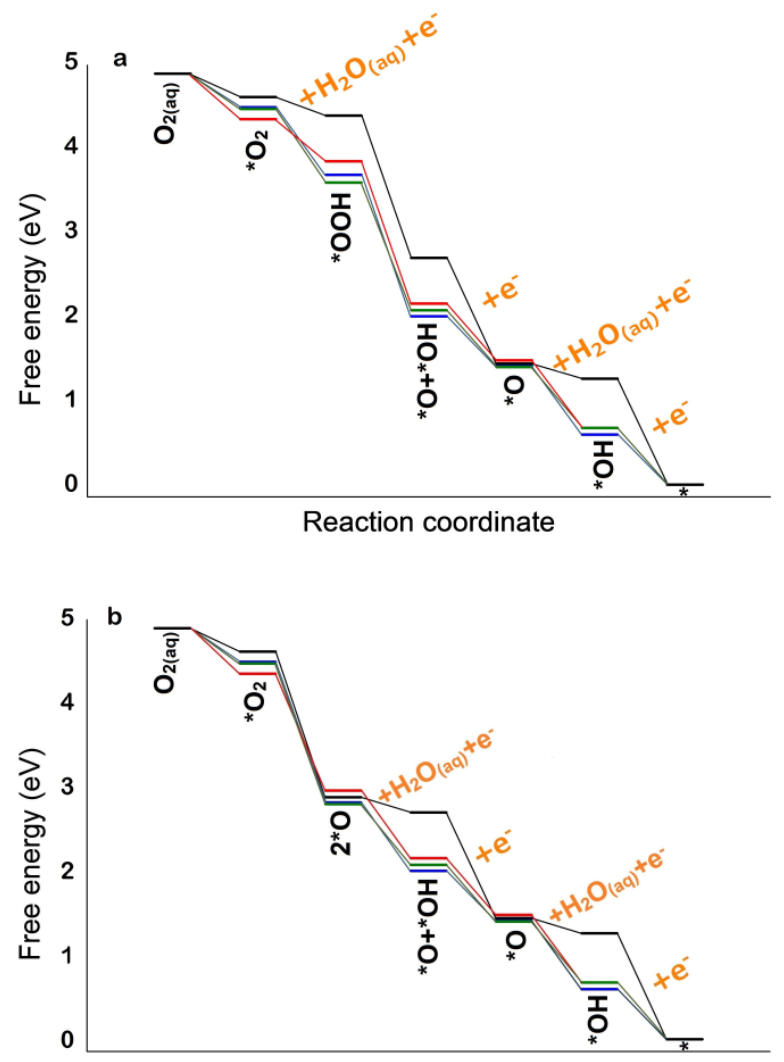

Reaction coordinate

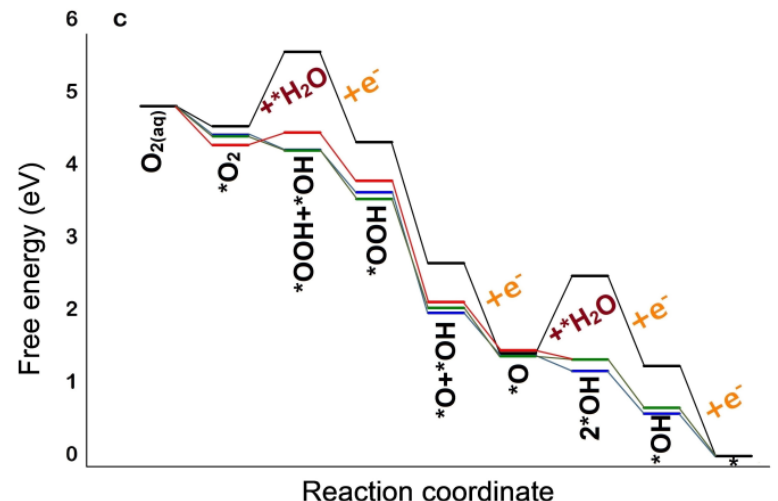

Figure 2. Free energy diagram of the ORR on $\operatorname{Pt}(111)$ surface via associative (a), dissociative (b) and $* \mathrm{H}_{2} \mathrm{O}$-mediated (c) mechansms. The free energy are from DFT calculation under 0V vs. RHE. The black line shows the reaction pathway on bare surface while red, blue and green lines represent the ORR with 1, 2 and 3 bilayers of water, respectively. 


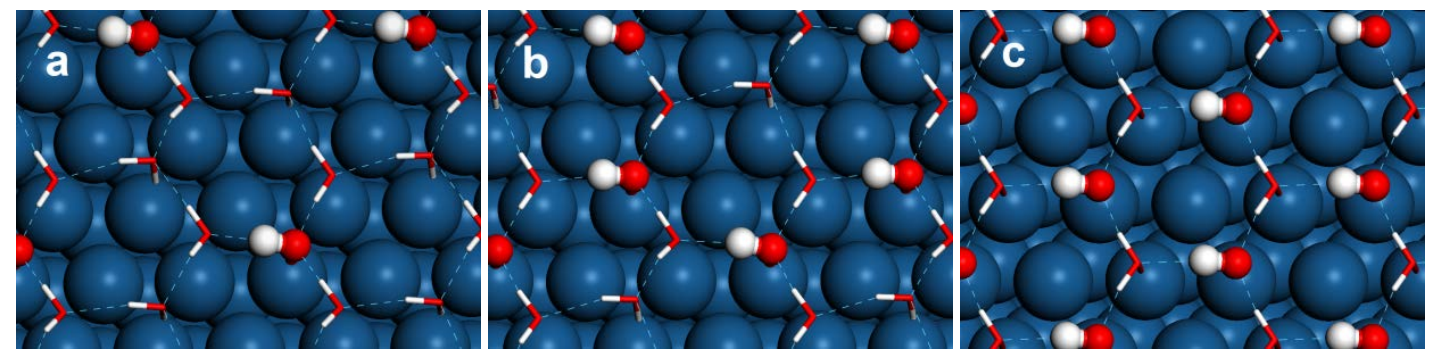

Figure 3. Optimized structures for $\mathrm{OH}$ adsorption on $\mathrm{OH} / \mathrm{H}_{2} \mathrm{O}$-covered $\mathrm{Pt}(111)$, where the coverage of $\mathrm{OH}$ varied from 1/9 ML (a), 2/9 ML (b) to 1/3 ML (c) (Blue: Pt; red: O; white: O; dashed blue lines: hydrogen bond). 

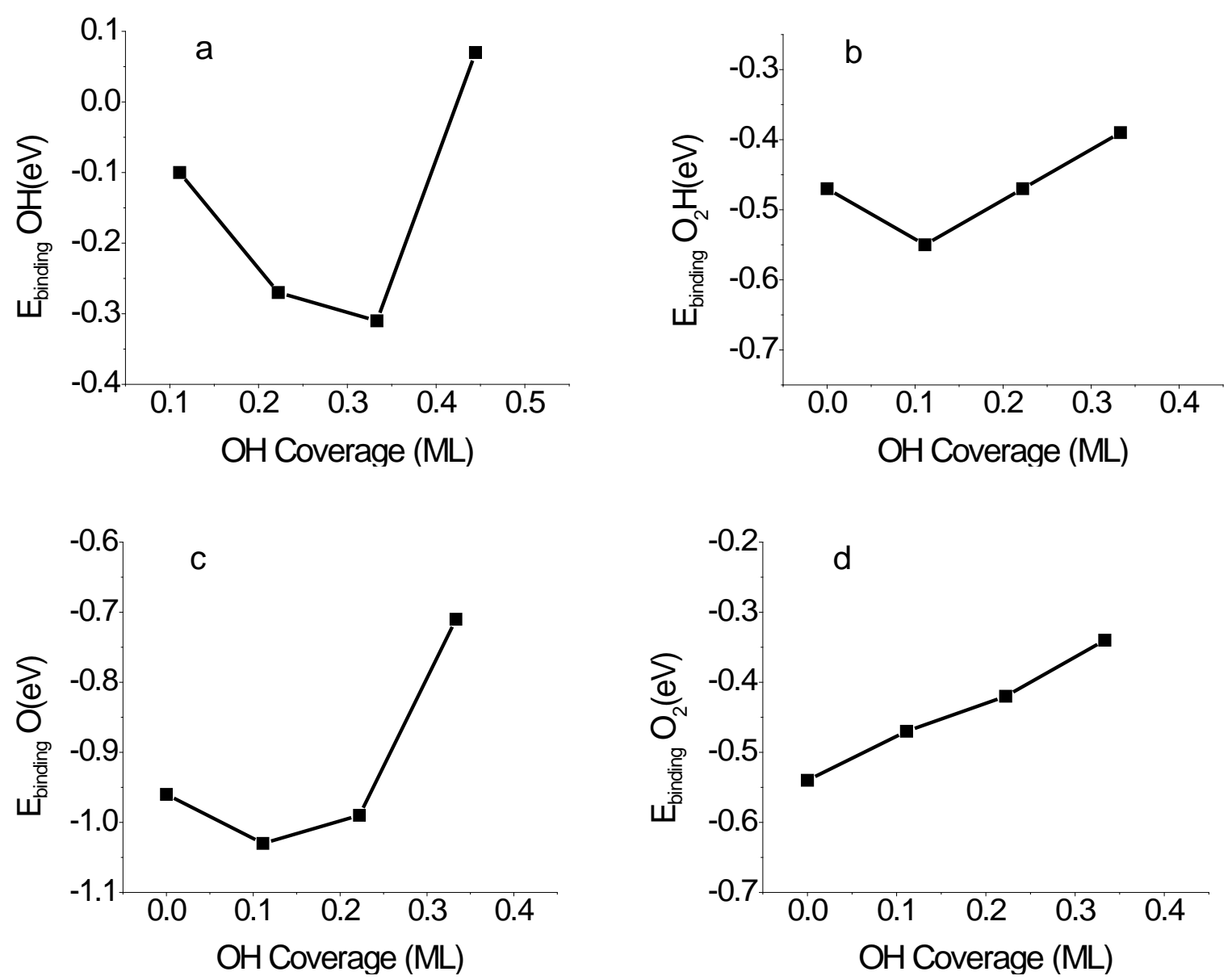

Figure 4. Differential binding energies of $* \mathrm{OH}(\mathrm{a}),{ }^{*} \mathrm{OOH}(\mathrm{b}),{ }^{*} \mathrm{O}$ (c) and ${ }^{*} \mathrm{O}_{2}(\mathrm{~d})$ as a function of $* \mathrm{OH}$ coverage. 


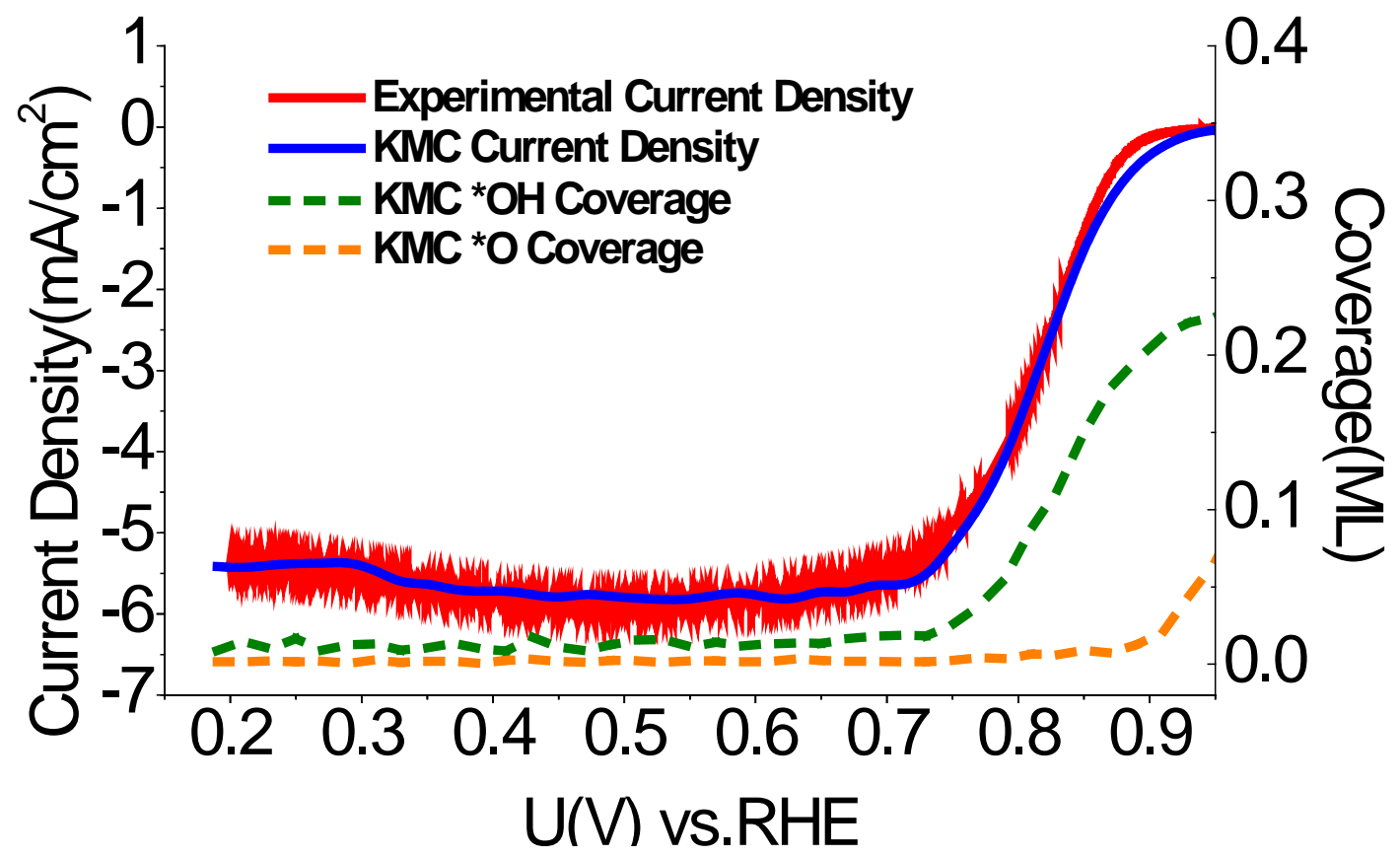

Figure 5. KMC-simulated polarization curve and surface coverage for the ORR on Pt(111) in 0.1 $\mathrm{M} \mathrm{KOH}$ at room temperature. The experimental results were cited from Ref. ${ }^{51}$. 


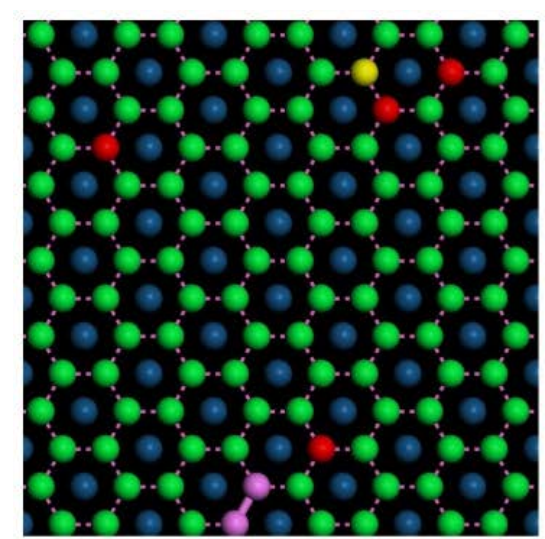

$\mathrm{U}=0.21 \mathrm{~V}$ vs. $\mathrm{RHE}$

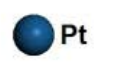

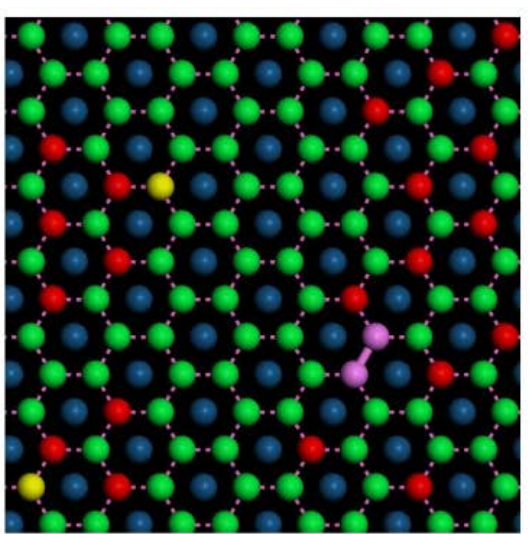

$U=0.83 \mathrm{~V}$ vs. $\mathrm{RHE}$

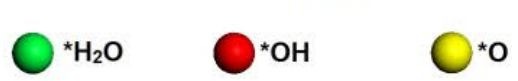

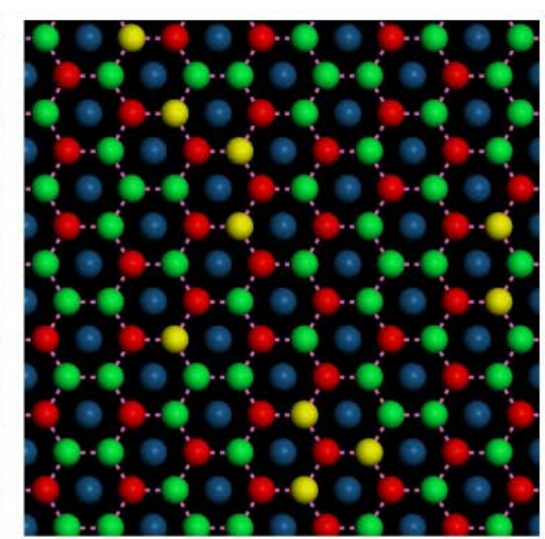

$\mathrm{U}=0.95 \mathrm{~V}$ vs. $\mathrm{RHE}$

Figure 6. Snapshots of $\mathrm{Pt}(111)$ under the ORR in $0.1 \mathrm{M} \mathrm{KOH}$ at room temperature on the basis of KMC simulations. 


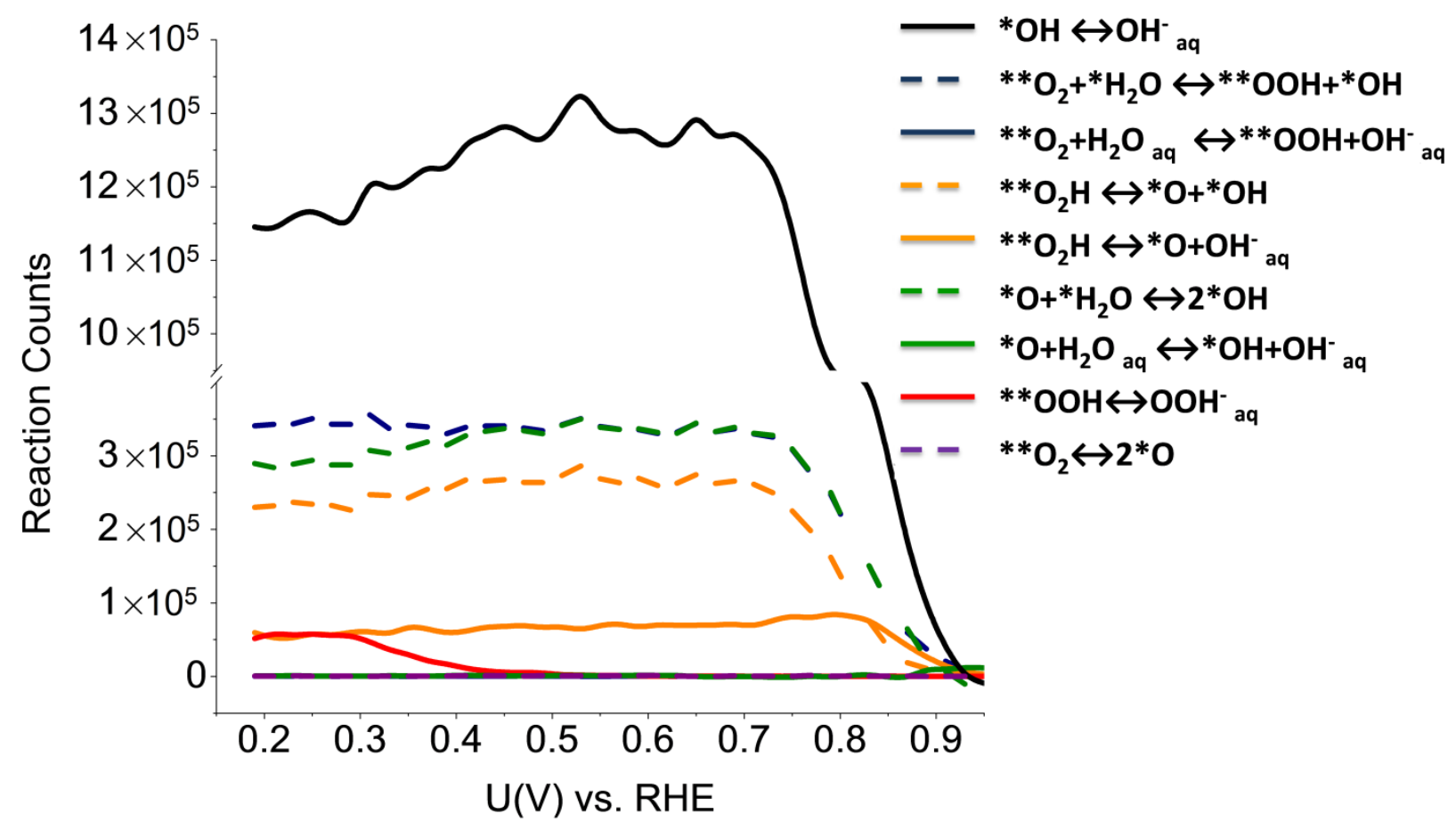

Figure 7. Reaction counts with respect to potential from KMC simulation of the ORR on Pt(111) in $0.1 \mathrm{M} \mathrm{KOH}$ at room temperature. 

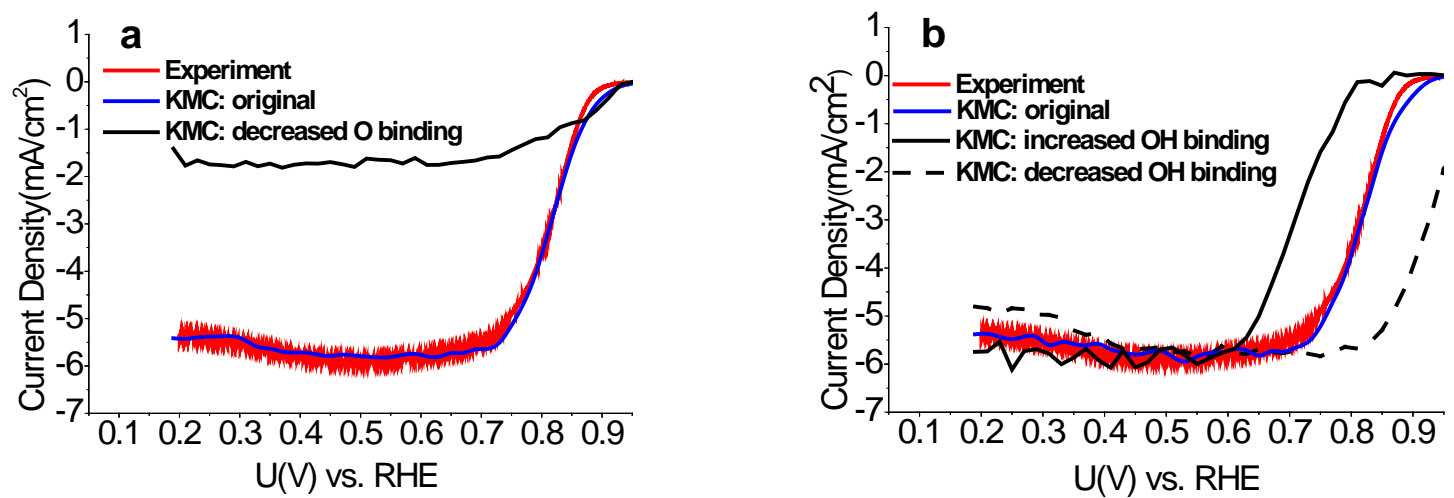

Figure 8. Sensitivity of polarization curve for the ORR on $\operatorname{Pt}(111)$ in $0.1 \mathrm{M} \mathrm{KOH}$ at room temperature in response to the variation in binding energy of reaction intermediates: ${ }^{* *} \mathrm{O}_{2}$ decreased by $0.2 \mathrm{eV}(\mathrm{a})$; * $\mathrm{OH}$ increased by $0.1 \mathrm{eV}$ and reduced by $0.1 \mathrm{eV}$ (b). 
Table of Contents

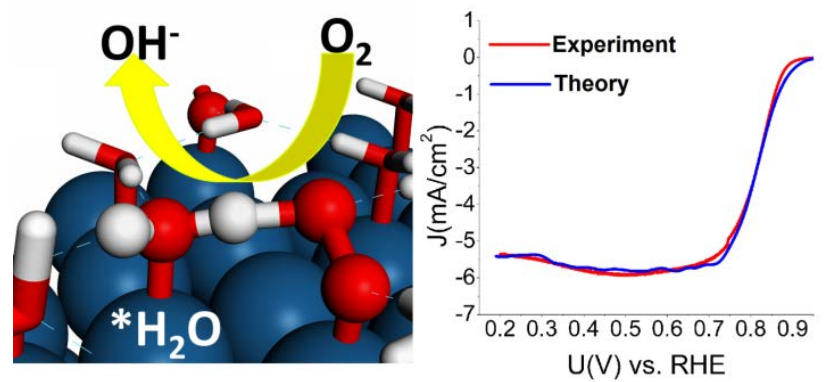

